\title{
Intraoperative Endocrine Injury, CTCAE
}

National Cancer Institute

\section{Source}

National Cancer Institute. Intraoperative Endocrine Injury, CT CAE. NCI Thesaurus. Code C143601.

A finding of damage to the endocrine gland during a surgical procedure. 